\title{
The Effects Gross Motor Skills in Pre-School Children have on Their Peer Relations and Social Status
}

\author{
${ }^{1}$ Hulya Gulay, ${ }^{2}$ Serdal Seven and ${ }^{3}$ Mustafa Damar \\ ${ }^{1}$ Department of Pre-School Education, Faculty of Education, \\ Pamukkale University, Kinikli Campus, Denizli, Turkey \\ ${ }^{2}$ Department of Pre-School Education, Faculty of Education, \\ Alparslan University, Mus, Turkey \\ ${ }^{3}$ The Ministry of National Education, Turkey
}

\begin{abstract}
The purpose of this study is to analyse the effects gross motor skills in preschool children between the ages of 5 and 6 have on their peer relations and social status. A relational survey method was used for this study. A total of 119 children between the ages of 5 and 6, attending a private nursery in Denizli, a province located in the Southwest of Turkey participated in the study. Results discovered that gross motor skills of preschool children have a significant predictive effect on their pro-social behaviour, aggression, asocial behaviour, exclusion, fear-anxiety, hyperactivity-distractibility, victimisation and the peer acceptance levels. The research results are striking in terms of illustrating the effects physical development in children has on the interaction between their peers.
\end{abstract}

Key words: Gross motor skills, preschool children, peer relationships, social status, aggression, Turkey

\section{INTRODUCTION}

There are numerous individual factors that affect peer relations during preschool. Factors that are said to affect peer relationships are gender, temperament, cognitive development, age variables as well as physical development (Dunn et al., 2007; Erwin, 1993; Gulay, 2010; Kostelnik et al., 2005). Gross motor development is a concept that is a part of physical development. Over time changes occur in motor behaviours that determine the relationship between an individual and its surrounding, this process is called developing motor skills (Crosby, 1994). The motor development is a learned sequence of movements that plays a huge role regarding social and behavioural expectations (Morrison, 2000). Developing a motor skill is mastering fundamental motor skills required for movement, balance, environmental awareness, research and playing games. Mastering these qualities depends on the child's physical, motor, social and psychological development (Williams and Monsma, 2007). The fundamental movement era (2-6 years), the turning point in terms of developing gross motor skills, occurs during preschool. During this period which establishes the foundations of developing motor skills, skills that form the foundation for more complex motor programmes start to develop (Gallahue and Ozmun, 2006;
Ulrich, 2000). Davies (2000) stated that gross motor skills affected the self esteem and peer relations of children. Studies proved that children with inadequate gross motor skills could be socially isolated within their peer groups. Motor skills and social skills during preschool are fields that affect the general development of children in the long-term (To et al., 2001). It is a known fact that children with inadequate motor and social skills experience difficulties in social relations, academic success and find it difficult to adjust to school in later years. In recent years, studies directed at analysing the peer relations of preschool children has started to increase in Turkey. Currently, there are no studies available that analyse the effect of physical development of small children on peer relations. Some of the studies, relating to gross motor skills during preschool, analyse the effects of training programmes directed at developing skills. A selection of other studies discussed the motor skills of children that suffer from development disorders such as cerebral palsy and orphans (Ozer and Ozer, 2004). The importance of this study is justified with the lack of studies available regarding the subject. Thanks to the research results of this study, the researchers will be able to put 4th, a dimension of the interaction between the physical and social development experienced in the early years of an individual's life. The purpose of this study is to analyse

Corresponding Author: Hulya Gulay, Department of Pre-School Education, Faculty of Education, Pamukkale University, Kinikli Campus, Denizli, Turkey 
the effects gross motor skills in preschool children between the ages of 5 and 6 have on their peer relations and social status. Ultimately, the aim of the study is to shed light on the interaction between peer relations and physical competencies. Following are the sub-objectives set in line with the main objective:

- Is the level of pro-social behaviour affected by the gross motor skills of children?

- Is the level of aggression affected by the gross motor skills of children?

- Is the level of asocial behaviour affected by the gross motor skills of children?

- Is the level of exclusion affected by the gross motor skills of children?

- Is the level of fear and anxiety affected by the gross motor skills of children?

- Is the level of hyperactivity and distractibility affected by the gross motor skills of children?

- Is the level of victimisation affected by the gross motor skills of children?

- Is the level of peer acceptance affected by the gross motor skills of children?

\section{MATERIALS AND METHODS}

A relational survey method was used for this study.

Participants: A total of 119 children between the ages of 5 and 6, attending a private nursery in Denizli, a province located in the Southwest of Turkey, participated in the study. In the study, 64 of the 119 students were girls $(53.8 \%)$ and $55(46.2 \%)$ of the 119 children were boys. Simple random sampling method was used to determine the sample group. The average age of the children was 5 years, 5 months and 22 days (minimum, 5 years; maximum, 6 years, 1 month and 10 days).

Test of gross motor development: Ulrich (2000) developed a 12 point test that evaluates the fundamental motor skills of children between the ages of 3 and 10 both disabled and able. The two subtests involved in the test that analyses, the 12 basic motor areas are locomotor and object control. The Locomotor test helps to analyse six skills; running, galloping, jumping, leaping, horizontal jumping and sliding.

The object control test also helps to analyse six skills; hitting stable balls, pushing balls while standing still, catch, football, throwing and hand ball. Every test is repeated three times; every time a skill is completed perfectly twice they are awarded 1 point and every time a skill is completed once or never, they are awarded 0 points. The points obtained are added up, the mean is calculated and the points for the two subtests are recorded. The total forms the motor skill test points (Gabbord, 1996; Gallahue and Ozmun, 2006).

The child behaviour scale: Ladd and Profilet (1996) developed this measurement tool to evaluate the peer relations of preschool children according to the information provided by their teachers. The scale consists of six subscales and a total of 44 items. The subscales are exhibiting aggression towards peers, exhibiting pro-social behaviour towards peers, exhibiting asocial behaviour towards peers, feeling fear and anxiety towards peers, exclusion by peers, hyperactivity (Ladd and Profilet, 1996). The researchers used all of the child behaviour scale, subscales in this study. All the items of the scale are evaluated in accordance with the expressions; never, sometimes and always.

In the studies, carried out in an effort to adapt the scale into Turkish, the internal consistency coefficient of the scale was determined as 0.81 at the end of the reliability and validity studies that were conducted after the linguistic equivalence study. The internal consistency coefficient of the subscale exhibiting aggression towards peers was 0.87 , the internal consistency coefficient of the subscale exhibiting pro-social behaviour towards peers was 0.88 , the internal consistency coefficient of the subscale exhibiting asocial behaviour towards peers was 0.84 , the internal consistency coefficient of the subscale fear and anxiety towards peers was 0.78 , the internal consistency coefficient of the subscale excluded by peers was 0.89 and the internal consistency coefficient of the subscale hyperactivity was 0.83 .

The peer victimisation scale: Ladd and KochenderferLadd (2002) developed this measurement tool based on the self reports of the Victimisation scale developed for children between the ages of 5 and 6 . The scale was completed by teachers. The scale includes a total of four items each of which focuses on one of the four types of peer aggression (physical, indirect, direct and general). Each item was evaluated using the expressions; never, sometimes and always (Ladd and Kochenderfer-Ladd, 2002). Gulay carried out the linguistic equivalence, the reliability and the validity studies of the scale. The internal consistency coefficient of the scale was 0.72 .

Picture sociometry scale: Asher et al. (1979) developed a scale where they showed every child in the class a photograph of their friends and asked them how much they liked the friend in the photograph. In accordance 
with the answer given by the child, the photograph is placed in a box with a smiley face (represents the answer: I like them very much), a straight face (represents the answer: I do not like them that much) or a sad face (represents the answer: I do not like them at all). Gulay adjusted the scale to Turkish with reliability and validity studies. Within the context of these studies, three more items were added to the scale by the researcher, making the final Turkish version a 4-point scale. The three questions added to the scale were; how much do you like sitting next to your friend? how much do you like carrying out activities with your friend? how much do you like playing with your friend? Throughout the adjustment studies, the internal consistency coefficient of the scale was $0.91 \quad(\mathrm{p}<0.001)$. The total points obtained by the Picture sociometry scale establish the social standing. A high total score represents the popularity within the peer group whereas a low total score represents unpopularity within the peer group and rejection.

Procedures: Permission was requested from school administration and parents regarding the applications prior to the data collection process. Teachers informed parents of the research. The test of gross motor development was carried out individually in the sports hall of the school by the children's PE (Physical Education) teacher. The child behaviour scale and the Peer victimisation scale were completed by the nursery teachers. The Picture sociometry scale was applied to every child individually by the researcher.

Data analysis: Research results were analysed using SPSS 13.0 software. The Pearson Product-Moment Correlation Coefficient (PMCC) and multiple regression methods were used to assess, the effects gross motor skills of children have on their peer relations and social standings.

\section{RESULTS AND DISCUSSION}

Table 1 shows a significant negative relationship between the gross motor skills of children and their aggression, asocial behaviour, exclusion, fear-anxiety, hyperactivity-distractibility and victimisation levels $(\mathrm{p}<0.05 ; \mathrm{p}<0.001)$. The higher the gross motor skills of children the lower the level of aggression, asocial behaviour, exclusion, fear-anxiety, hyperactivity distractibility and victimisation. In the same way, the lower the gross motor skills of children, the higher the level of aggression, anti-social behaviour, exclusion, fear-anxiety, hyperactivity-distractibility and victimisation. Additionally, a significant positive relationship was determined between the gross motor skills of children and their pro-social behaviour and peer acceptance levels $(\mathrm{p}<0.05 ; \mathrm{p}<0.001)$.

Pro-social behaviour and peer acceptance levels increase together with the increase in gross motor skills of children. Pro-social behaviour and peer acceptance levels decrease together with the decrease in gross motor skills of children. Table 2 shows how gross motor skills of children have a predictive effect on the pro-social behaviour, aggression, asocial behaviour, exclusion, fearanxiety, hyperactivity-distractibility, victimisation and the peer acceptance levels $(p<0.05 ; p<0.001)$ of children. Results discovered that gross motor skills of preschool children have a significant predictive effect on their prosocial behaviour, aggression, asocial behaviour, exclusion, fear-anxiety, hyperactivity-distractibility, victimisation and the peer acceptance levels.

Pro-social behaviour and peer acceptance levels increase together with the increase in gross motor skills of children. The lower the gross motor skills of children the higher the level of aggression, asocial behaviour, exclusion, fear-anxiety, hyperactivity distractibility and victimisation.

The research results are striking in terms of illustrating the effects physical development in children has on the interaction between their peers. The reason behind this could be that children with motor skills are more likely to succeed in games and activities in comparison to their peers with inadequate motor skills. This success and the continuity of this success can also increase depending on their self-confidence and how

Table 1: Descriptive statistic, means, SD and correlations matrix

\begin{tabular}{|c|c|c|c|c|c|c|c|c|c|c|}
\hline Variables & Means \pm SD & 1 & 2 & 3 & 4 & 5 & 6 & 7 & 8 & 9 \\
\hline Gross motor skills & $40.39 \pm 6.72$ & - & & & & & & & & \\
\hline Pro-social behaviour & $14.49 \pm 4.15$ & $0.44^{* * *}$ & - & & & & & & & \\
\hline Aggression & $1.28 \pm 1.64$ & $-0.20^{*}$ & $-0.55^{* * *}$ & - & & & & & & \\
\hline Asocial behaviour & $0.74 \pm 1.29$ & $-0.29^{* * *}$ & $-0.35^{\text {*** }}$ & 0.08 & - & & & & & \\
\hline Exclusion & $0.81 \pm 1.54$ & $-0.18^{*}$ & $-0.33^{* * *}$ & $0.40^{* * *}$ & $0.36^{* * *}$ & - & & & & \\
\hline Fear-anxiety & $1.81 \pm 2.41$ & $-0.38^{* * *}$ & -0.15 & -0.01 & 0.04 & 0.00 & - & & & \\
\hline Hyperactivity-distractibility & $1.38 \pm 2.01$ & $-0.24^{* * *}$ & $-0.48^{* * *}$ & $0.49^{* *}$ & -0.04 & 0.04 & $0.25^{* * *}$ & - & & \\
\hline Victimisation & $0.10 \pm 0.39$ & $-0.20^{*}$ & $-0.32^{* * *}$ & $0.48^{* * *}$ & 0.08 & $0.34^{* * *}$ & 0.00 & $0.32^{* * *}$ & - & \\
\hline Peer acceptance & $3.37 \pm 2.41$ & $0.18^{*}$ & -0.02 & $0.26^{* * *}$ & 0.04 & 0.06 & -0.15 & 0.10 & 0.16 & - \\
\hline
\end{tabular}

$\mathrm{N}=119 ; * \mathrm{p}<0.05 ; * * \mathrm{p}<0.001$ 
Res. J. Biol. Sci., 5 (11): 722-726, 2010

Table 2: Results of multiple regression analysis conducted for predicting gross motor skills

\begin{tabular}{lccclc} 
Variables & $\mathrm{T}$ & $\mathrm{T}$ & $\mathrm{R}$ & $\mathrm{R}^{2}$ & $\mathrm{~F}$ \\
\hline Pro-social behaviour & 0.44 & $5.313^{* * *}$ & 0.44 & 0.19 & $(1,118)=28.229^{* * * *}$ \\
Aggression & 0.20 & $-2.176^{* *}$ & 0.20 & 0.04 & $(1,118)=4.737^{*}$ \\
Asocial behaviour & -0.29 & $-3.307^{* *}$ & 0.29 & 0.09 & $(1,118)=10.936^{* * *}$ \\
Exclusion & -0.18 & $-1.987^{*}$ & 0.19 & 0.03 & $(1,118)=3.947^{*}$ \\
Fear-anxiety & -0.38 & $-4.431^{* *}$ & 0.38 & 0.14 & $(1,118)=19.638^{* * *}$ \\
Hyperactivity-distractibility & -0.24 & $-2.653^{* *}$ & 0.24 & 0.06 & $(1,118)=7.037^{* * *}$ \\
Victimisation & -0.20 & $-2.184^{*}$ & 0.20 & 0.04 & $(1,118)=4.770^{*}$ \\
Peer acceptance & 0.18 & $1.999^{*}$ & 0.18 & 0.03 & $(1,118)=3.997^{*}$ \\
\hline
\end{tabular}

$\mathrm{N}=119 ;{ }^{*} \mathrm{p}<0.05 ; * * \mathrm{p}<0.001$

well they are respected among their peers. In time, the interaction between the variables of success, selfconfidence and peer acceptance turns into a cycle. In the same way, gross motor skill disorders or inadequate gross motor skills may reduce the participation rate in activities. As a result, the children may isolate themselves from social surroundings and become passive in class. Ultimately, this might give rise to introvert reactions such as passiveness, isolation and introversion or extrovert reactions such as aggressive/repressive behaviour. Having certain physical capabilities may support children in becoming group leaders in games. Properties such as leadership and physical supremacy may increase peer popularity. As a result, children with adequate gross motor skills have an important advantage in terms of peer acceptance. In terms of victimisation as children with gross motor skills are successful, superior and in fact leaders in their peer groups, they are less likely to suffer peer victimisation. Hyperactive children with gross motor skills may be unsuccessful in tasks as they are unable to control when and how they should use their skills. In general, the results obtained by the research complement each other. Gross motor skills allow children to play a larger variety of games as they develop their game skills. Children learn about team work, helping each other, complaisance, sharing, respecting their friends and game rules and controlling their emotions by participating in physical activities and active games that are an important part of preschool.

They learn about their bodies and capabilities while playing games as well as learning to express themselves (Johnson, 1999). As playing games is the most important part of peer groups, gross motor skills are the common factor for peer relations and playing games. As well as being inadequate both worldwide and across Turkey studies that contain gross motor skills and peer relationships variables together are not common this is what makes this study unique as well as proving the necessity of such studies. Some researches (Schoemaker and Kalverboer, 1994; Stott et al., 1984) stated that there was a positive relationship between poor motor coordination and social/emotional difficulties in children aged 6-9 years. Long-term researches regarding the subject (Shaffer et al., 1985; Sigurdsson et al., 2002) stated that early motor impairment during preschool may be the reason behind anxiety issues experienced during puberty. In a long-term study, the relationship between anxiety and depression and motor develop was scrutinised for fifty 4 years old children at age 6 and 12 years (Piek et al., 2010). In conclusion, a relationship between gross motor skills in young children and the depression and anxiety disorders experienced at school was highly likely. While physically capable children are popular within their peer group and accepted as capable by their peers, weaker children are exposed to criticism, isolation and bullying by their peers. Moreover, studies conducted on preschool and primary school children prove that children with adequate physical ability are more social, more positive, less aggressive and more attractive (Dunn et al., 2007; Erwin, 1993; Kostelnik et al., 2005). In a study conducted by Sadock et al. (2007), they stated that children unable to perform in games and activities that require agility, experienced issues within their peer groups. It is obvious that an interaction exists between developing motor skills, peer relations and peer acceptance.

This study has some limitations. In line with these limitations, the number of children in the sample group should be increase and a research having long-term observation studies should be planned in future studies. As well as gross motor skills, other variables should also be investigated to see which ones affect the physical developments of children (height, weight, hair, glasses, clothes, etc.). How different variables (gender, age, attitude of parents, etc.) together with gross motor skills have an effect on peer relations and peer acceptance should be investigated.

\section{CONCLUSION}

Research results describes that it is highly likely that gross motor skills of children, aged between 5 and 6 , affect their peer relations and peer acceptance. This result proves that there is interaction between physical development and social development. In the event that we accept, development as a whole studies must be carried 
out in all development areas in children attending nursery. Attention must be paid to how the physical competencies of children affect the peer group dynamics and social relations.

\section{REFERENCES}

Asher, S.R., L.C. Singleton, B.R. Tinsley and S. Hymel, 1979. A reliable sociometric measure for preschool children. Develop. Psychol., 15: 443-444.

Crosby, F.J., 1994. Understanding affirmative action. Basic Applied Soc. Psychol., 15: 13-41.

Davies, N.J., 2000. Chiropratic Pediatrics: A Clinical Handbook. Harcourt Publisher, China.

Dunn, J.C., J.G.H. Dunn and A. Bayduza, 2007. Perceived athletic competence, sociometric status, and loneliness elementary school children. J. Sport Behav., 30: 249-263.

Erwin, P., 1993. Friendship and Peer Relations in Children. John Wiley and Sons Publishers, New York.

Gabbord, C.P., 1996. Lifelong Motor Development. 2nd Edn., Brown and Benchmark Publishers, USA.

Gallahue, D.L. and J.G. Ozmun, 2006. Understanding Motor Development: Infants, Children, Adolescents, Adults. 6th Edn., McGraw-Hill Companies, USA.

Gulay, H., 2010. Peer Relationships in Preshool Period. PegemA Publishing, Ankara.

Johnson, J.E., 1999. Play and Early Childhood Development. 2nd Edn., Addison Wesley Longman, USA.

Kostelnik, M.J., A.P. Whiren, A.K. Soderman and K. Gregory, 2005. Guiding Children's Social Development. Theory to Practice. Thomson and Demler Learning, USA.

Ladd, G.W. and B. Kochenderfer-Ladd, 2002. Identifying victims of peer aggression from early to middle childhood: Analysis of cross-prevalance of victimization and characteristics of identified victims. Psychol. Assessment, 14: 74-96.

Ladd, G.W. and S.M. Profilet, 1996. The child behavior scale: A teacher-report measure of young children's aggressive, withdrawn, and prosocial behaviors. Develop. Psychol., 32: 1008-1024.
Morrison, G.S., 2000. Fundamentals of Early Childhood Education. 2nd Edn., Merrill Prentice Hall, Inc., USA.

Ozer, D. and M. Ozer, 2004. Motor Development in Children. Nobel Publishing, Ankara.

Piek, J.P., N.C. Barrett, L.M. Smith, D. Rigoli and N. Gasson, 2010. Do motor skills in infancy and early childhood predict anxious and depressive symptomatology at school age. Human Movement Sci., 29: 777-786.

Sadock, B.J., H.I. Kaplan and V.A. Sadock, 2007. Kaplan and Sadock's Synopsis of Psychiatry: Behavioral Sciences/Clinical Psychiatry. Lippincott Williams and Wilkins Publishers, USA.

Schoemaker, M.M. and A.F. Kalverboer, 1994. Social and affective problems of children who are clumsy: How early do they begin. Adapted Phys. Activity Quarterly, 11: 130-140.

Shaffer, D., I. Schonfeld, P.A. O'Connor, C. Stokman, P. Trautman, S. Shafer and S. Ng, 1985. Neurological soft signs: Their relationship to psychiatric disorder and intelligence in childhood and adolescence. Arch. General Psychiatry, 42: 342-351.

Sigurdsson, E., J. van Os and E. Fombonne, 2002. Are impaired childhood motor skills a risk factor for adolescent anxiety: Results from the 1958 UK birth cohort and the national child development study. Am. J. Psychiatry, 159: 1044-1066.

Stott, D.H., F.A. Moyes and S.E. Henderson, 1984. The Henderson Revision of the Test of Motor Impairment. Psychological Corporation, San Antonio, TX.

To, T., S.M. Gadarette and Y. Liu, 2001. Biological, social and environmental correlates of preschool development. Child Care Health Develop., 27: 187-200.

Ulrich, D., 2000. Test of Gross Motor Development. Examiner's Manual. 2nd Edn., PRO-ED, Austin, Texas.

Williams, H.G. and E.V. Monsma, 2007. Assessment of Gross Motor Development. In: Psychoeducational Assessment of Preschool Children, Bracken, R. and J. Nagle (Eds.). Lawrance Earlbaum Publishers, USA, pp: $397-435$. 